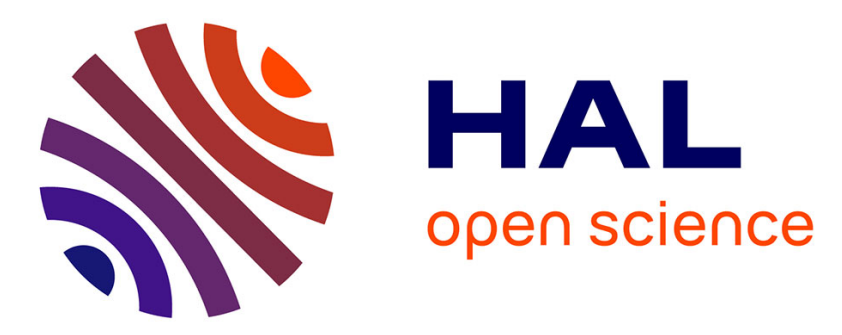

\title{
Flow neutralisation of sulfur-containing chemical warfare agents with Oxone: packed-bed vs. aqueous solution
} Antonin Delaune, Sergui Mansour, Baptiste Picard, Philippe Carrasqueira, Isabelle Chataigner, Ludovic Jean, Pierre-Yves Renard, Jean-Christophe M Monbaliu, Julien Legros

\section{To cite this version:}

Antonin Delaune, Sergui Mansour, Baptiste Picard, Philippe Carrasqueira, Isabelle Chataigner, et al.. Flow neutralisation of sulfur-containing chemical warfare agents with Oxone: packed-bed vs. aqueous solution. Green Chemistry, 2021, 23 (8), pp.2925-2930. 10.1039/D1GC00449B . hal-03353823

\section{HAL Id: hal-03353823 \\ https://hal.science/hal-03353823}

Submitted on 28 Sep 2021

HAL is a multi-disciplinary open access archive for the deposit and dissemination of scientific research documents, whether they are published or not. The documents may come from teaching and research institutions in France or abroad, or from public or private research centers.
L'archive ouverte pluridisciplinaire HAL, est destinée au dépôt et à la diffusion de documents scientifiques de niveau recherche, publiés ou non, émanant des établissements d'enseignement et de recherche français ou étrangers, des laboratoires publics ou privés. 


\section{Flow neutralisation of sulfur-containing chemical warfare agents with Oxone: packed-bed vs. aqueous solution}

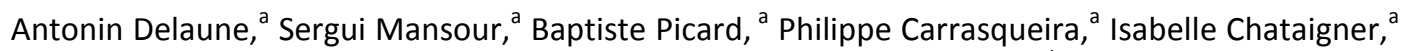
Ludovic Jean, ${ }^{a}$ Pierre-Yves Renard, ${ }^{a}$ Jean-Christophe M. Monbaliu, ${ }^{b}$ and Julien Legros, ${ }^{*}$

The oxidative neutralisation of sulfur-containing CWA (yperite and VX simulants) with Oxone has been developped in flow systems. In order to reach full selectivity towards harmless decomposition products, Oxone has to be used either under solid form (blister agents detoxification) or aqueous form (nerve agents detoxification).

\section{Introduction}

The development of new technologies and methods for the neutralization of chemical warfare agents (CWAs) is an issue of the utmost importance due to the remaining stockpiles of past conflicts and their use in recent dramatic events in Syria, Malaysia, Great-Britain and Russia. ${ }^{1-3}$ Among these CWAs, sulfur mustards and $V$-series of organophosphorous nerve agents (OPNA) are known to be very persistent in the environment since they are particularly reluctant to hydrolysis. Noteworthy, both these CWAs contain a pivotal sulfur atom that is responsible for their toxicity (Fig 1). Indeed, due to the sulfur anchimeric assistance, the 'mustard gas' (yperite, HD) is in equilibrium with the very electrophilic -and therefore highly toxic- episulfonium form. Regarding $\mathrm{V}$-series nerve agents, the $-\mathrm{S}-\left(\mathrm{CH}_{2}\right)_{2}-\mathrm{N}(\mathrm{Alk})_{2}$ key motif offers a moderate leaving group ability and therefore a good stability; it perfectly simulates acetylcholine and V-series OPNA thus react with irreversible consequences on neurotransmission through inhibition of a key nerve impulse regulatory enzyme, namely AChE (acetylcholinesterase). ${ }^{4}$ As a matter of fact, this devastating sulfur atom can also be the Achilles' heel of these CWA if very specific and selective conditions are applied, as detailed below.

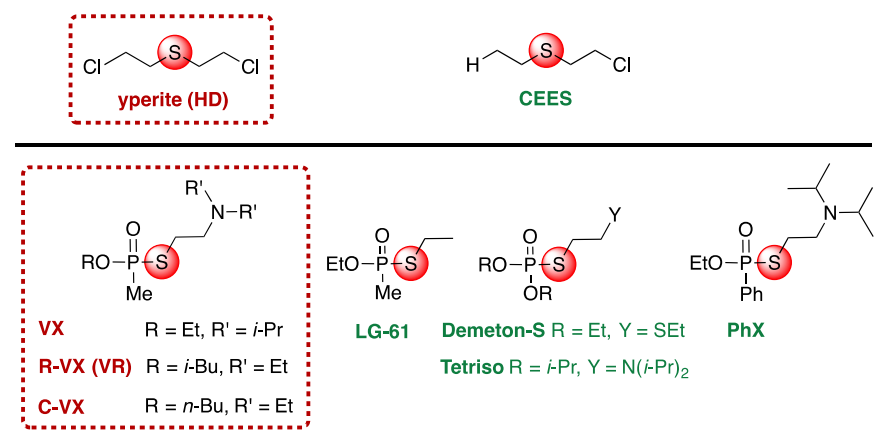

Fig. 1. Sulfur mustard HD, V-series CWA (left) and corresponding simulants (right).
Since the neighbouring group participation of the sulfur atom in the yperite leads to the corresponding harmful episulfonium ion, disrupting this anchimeric assistance is an excellent strategy for neutralising HD. Thus the oxidation of HD into the innocuous sulfoxide HDO has been shown to a powerful method of neutralisation. The selectivity of the sulfoxidation is essential because overoxidation affords the sulfone $\mathrm{HDO}_{2}$, which quickly decomposes into the highly electrophilic and toxic divinyl sulfone $\mathrm{DVSO}_{2}$ (Fig. 2, top). To prevent this overoxidation, the neutralisation of the hydrophobic sulfur mustards with aqueous oxidants is very difficult to control and require the use of microemulsions with variable results. ${ }^{5-8}$
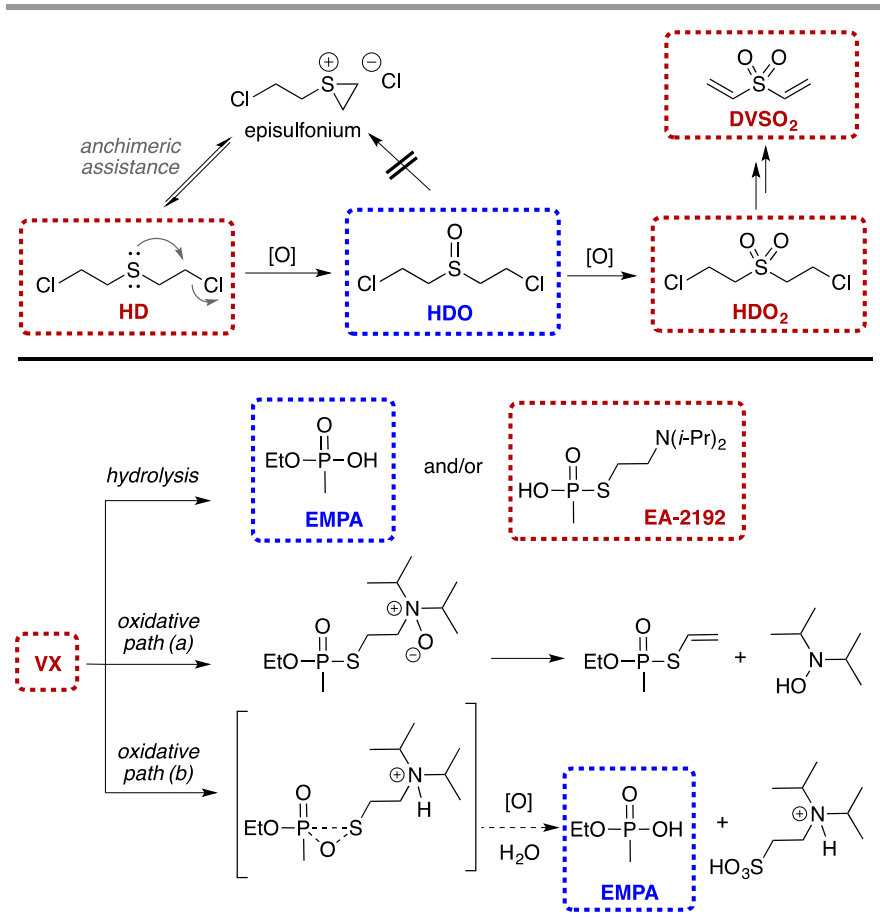

Fig. 2. Neutralisation path of yperite (HD) and VX.

In V-series OPNA, the aminoethanethiol moiety is a poor leaving group (Fig. 2, bottom), responsible for its persistent properties. For example, not only the lead compound VX is very reluctant to simple hydrolysis, but it even affords two distinct organophosphorous molecules with separate bioactivities according to the selectivity of the cleavage. When the P-S bond is broken, the harmless (and desired) EMPA (ethyl methylphosphonic acid) is formed while the $\mathrm{P}-\mathrm{O}$ bond cleavage 
yields the still toxic and stable phosphonic acid (EA-2192) (Fig. 2).‡ Therefore, a fully selective cleavage of the phosphorussulfur bond of $\mathrm{V}$ type nerve agents is an absolute requisite in order to completely neutralize these CWAs. In 1990, Yang demonstrated that the oxidation-assisted neutralization of $\mathrm{VX}$ was very effective under acidic conditions, ${ }^{9,10}$ while the use of a neutral electrophilic oxidant yielded a vinyl thiophosphonate of unknown toxicity. Thus, use of an oxaziridine caused the formation of an $\mathrm{N}$-oxide that further underwent a dehydroamination with release of a hydroxylamine derivative and of the vinyl thiophosphonate (Fig. 2, oxidative path (a)). In contrast, the application of 3 equivalents of diluted aqueous acidic potassium caroate $\left(\mathrm{KHSO}_{5}\right)$, under commercial form Oxone ${ }^{\circledR}$ or Caroate $\left(2 \mathrm{KHSO}_{5} \mathrm{KHSO}_{4} \mathrm{~K}_{2} \mathrm{SO}_{4}\right)$, allowed full decontamination. Whereas the exact mechanism remains unclear, the acidity of the medium clearly prevented the $\mathrm{N}$ oxidation through the formation of an ammonium derivative, allowing the oxygen transfer selectively on the sulfur atom. These acidic aqueous conditions and $\mathrm{KHSO}_{5}$ excess allowed formation of harmless EMPA along with amino sulfonic acid as depicted in Fig.2, path (b).

The development of a unique method, able to efficiently decontaminate various sulfur-containing CWA with full selectivity is thus a major challenge. Recently, a group from Israel reported two interesting methods leading to the abatement of both $\mathrm{HD}$ and $\mathrm{VX}$ agents: either mediated by $\mathrm{H}_{2} \mathrm{O} / \mathrm{I}^{+}$(from NIS) ${ }^{11}$ or with the reagent Me-DABCOF. ${ }^{12}$ In both cases, the protocols release stoichiometric amounts of organic byproducts to be further disposed along with the transformed CWA. Moreover, such protocols might be difficult to upscale. In this context, the use of miniaturised reactors operated in continuous flow have been shown to be invaluable tools to reach high selectivity sometimes unavailable under classical batch conditions. ${ }^{13-20}$ Moreover, such devices offer the possibility to handle and treat large volumes of toxic and corrosive compounds without exposing the operator. ${ }^{21,22}$ These features make them thus ideal tools for the sustainable decontamination of chemical warfare agents with strong oxidants. In 2017, we showed for the first time that the neutralization of the HD simulant CEES could be efficiently performed with a combination of hydrogen peroxide and methanesulfonic acid under continuous flow. ${ }^{23}$ With a short residence time $\left(t^{R}<4 \mathrm{~min}\right)$, the reaction afforded only the innocuous sulfoxide CEESO without any overoxidation toward the toxic sulfone $\mathrm{CEESO}_{2}$. In the same vein, Monbaliu developed an alternative green method with ${ }^{1} \mathrm{O}_{2}$ as oxidizing agent. This latter was generated directly from air and light in the flow system allowing the fully selective sulfoxidation of CEES without organic byproducts. ${ }^{24}$ However, no flow system has ever been developed for the oxidative decontamination of OPNA. ${ }^{9,25-28}$ Along these lines we now report that the effective neutralisation of sulfur mustards and V-series OPNA can be performed through controlled oxidation at the sulfur atom with Oxone in an adapted flow system.

\section{General information}

PhX was synthesized according to the literature. ${ }^{29}$ CEES and Oxone were purchased and used as provided; solvents were used without further purification. All fluidic tubing, connections, adapters were manufactured by IDEX Health and Science. Syringe pumps were manufactured by Harvard apparatus (Pump 11 Elite Dual). Air tight plastic syringe were used in all experiments.

All reactions were conducted at room temperature $\left(20-25^{\circ} \mathrm{C}\right)$ except if noted otherwise, with no particular precautions with regard to residual moisture and air. However due to the toxicity of CWA simulants, reactions were carried out under closed atmosphere in a very well-ventilated fume hood. All glassware and materials in contact of simulants were immersed in a bleach bath under the fume hood for one day before further washing and/or disposal.

\section{General procedure for the flow oxidation of CWA simulant CEES in an Oxone packed-bed reactor}

CEES $(50 \mathrm{mg}, 0.4 \mathrm{mmol}$ ) was dissolved in a solution of ethanol/trifluoracetic acid $(1: 1 \mathrm{v} / \mathrm{v}, 2 \mathrm{~mL})$. After flushing the packed-bed reactor filled with Oxone (see ESI) with ethanol, the reagent solution was introduced in an air-tight plastic syringe $(2.5 \mathrm{~mL})$ and injected through the column with a flow rate of $1 \mathrm{~mL}$. $\mathrm{min}^{-1}$ by using syringe pump. When injected, a solution of ethanol/trifluoroacetic acid $(1: 1 \mathrm{v} / \mathrm{v}, 10 \mathrm{~mL})$ was introduced with an air-tight plastic syringe into the device at a flow rate of $1 \mathrm{~mL}$. $\mathrm{min}^{-1}$ to rinse it. The solution was collected in a round bottomed flask containing an aqueous solution of $\mathrm{Na}_{2} \mathrm{~S}_{2} \mathrm{O}_{3}(30 \% \mathrm{w} / \mathrm{w})$, under stirring. The solution was neutralized with aqueous solution of $\mathrm{K}_{2} \mathrm{CO}_{3}$, extracted with 25 $\mathrm{mL}$ of ethyl acetate, dried over $\mathrm{MgSO}_{4}$, filtered and concentrated in vacuo to afford a pure product, analyses by GC-MS and NMR. CEESO was obtained as a slightly reddish oil (55.1 mg, 98\% yield).

\section{General procedure for the neutralization of CWA simulant PhX by enriched Oxone ${ }^{\circledR}$ under flow conditions}

Neat $\mathrm{PhX}$ was injected at a flow rate of $2.16 \mu \mathrm{L} \cdot \mathrm{min}^{-1}$ for 10 minutes. Enriched Oxone (1/3 diluted) was injected at a 38.84 $\mu \mathrm{L}$. $\mathrm{min}^{-1}$ flow rate for 20 minutes. These two substrates were mixed together in a PEEK T-shaped micromixer (1/16 in). The main reactor was made of a $20.38 \mathrm{~cm}$ long PFA tubing (OD = $1 / 8 \mathrm{in}$., ID $=1.56 \mathrm{~mm}, \mathrm{~V}=410 \mu \mathrm{L}$ ). The reaction proceeded in the reactor for $t^{R}=10$ minutes $\left(Q_{\text {tot }}=41 \mu \mathrm{L} \cdot \mathrm{min}^{-1}\right)$, where the medium quickly became homogeneous, before being collected in a tube containing the $30 \%(\mathrm{w} / \mathrm{w})$ aqueous solution of $\mathrm{Na}_{2} \mathrm{~S}_{2} \mathrm{O}_{3}$ under strong magnetic stirring in order to quench the oxidant. The reaction medium was extracted with ethyl acetate, the recovered organic phase was dried over $\mathrm{MgSO}_{4}$, filtered and concentrated in vacuo to afford phenylphosphonic acid monoethyl ester as a slightly yellowish oil $(13.70 \mathrm{mg}, 97 \%$ yield).

\section{Results and discussion}

\section{Experimental section}


Oxone $^{\circledR}$ is a stable, inexpensive and innocuous oxidant. This crystalline solid is almost only soluble in water. ${ }^{30}$ Under classical batch conditions, the treatment of the lipophilic $\mathrm{HD}$ with aqueous Oxone ${ }^{\circledR} \quad\left(\mathrm{KHSO}_{5} \cdot 0.5 \mathrm{KHSO}_{4} \cdot 0.5 \mathrm{~K}_{2} \mathrm{SO}_{4}\right)$ affords undesired sulfones as major products (mostly mono- and divinylsulfone). ${ }^{31}$ In our hands, the overoxidation path was confirmed with CEES as substrate. Even with 1 eq. of aqueous Oxone $37 \%$ of $\mathrm{CEESO}_{2}$ were obtained along with CEES, ruling out aqueous batch conditions as a selective method for neutralization. ${ }^{32}$

Due to superior mass transfer and fine residence time control obtained in flow microreactors consecutive competitive reactions can sometimes be avoided with significant enhancement in selectivity. ${ }^{13-15,23,24,33-40}$ Thus, we implemented a flow system where a methanolic solution of CEES was introduced at the first inlet and an aqueous solution of Oxone $\left(C=0.59 \mathrm{~mol} . \mathrm{L}^{-1}\right)$ at the second inlet, the reactor outlet being quenched with a solution of $\mathrm{NaHSO}_{3}$ (Fig. 3, Method A). Unfortunately, as soon as the organic solution met the aqueous phase in the T-mixer, salts precipitated with immediate clogging of the flow system. The same problem occurred with MeCN as solvent even with highly diluted solution of CEES and Oxone. An alternative possibility was to work under biphasic conditions using CEES neat or in heptane with alternate organic-aqueous slugs. Here also, the results were disappointing with recurrent clogging problems and no reproducibility in the sulfide/sulfoxide/sulfone ratio.

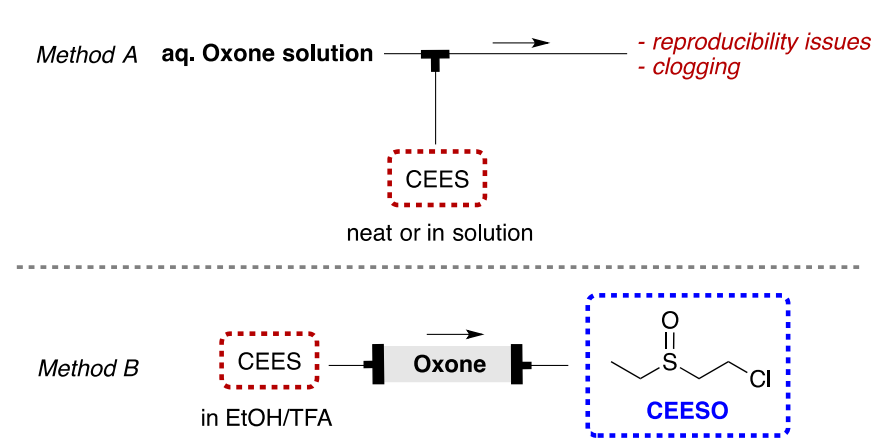

Fig. 3. Oxidative neutralization of HD simulant CEES with Oxone.

In 2018, Wirth developed an interesting alternative flow approach circumventing such liquid biphasic issues with Oxone by switching to a solid-liquid system: the Oxone-mediated sulfoxidation was performed using a packed-bed reactor filled with the solid oxidant. ${ }^{41}$ In this setup rather simple sulfides (in DCM/TFA) were injected at the reactor inlet and the corresponding sulfoxide was afforded at the outlet after $4 \mathrm{~min}$ residence time. We therefore transposed this method to CEES, albeit by replacing DCM by EtOH as a safer alternative solvent (EtOH/TFA, 1:1; Fig. 3, Method B). Optimisation of the conditions is reported in Table 1.

\begin{tabular}{|c|c|c|c|c|c|}
\hline \multirow{2}{*}{ Entry } & \multirow{2}{*}{$\begin{array}{l}\text { Flow rate } \\
\left(\mathrm{mL} . \mathrm{min}^{-1}\right)\end{array}$} & \multirow{2}{*}{$t^{R}(\min )$} & \multicolumn{3}{|c|}{ Product ratio $(\%)^{b}$} \\
\hline & & & CEES & CEESO & $\mathrm{CEESO}_{2}$ \\
\hline 1 & 1.25 & 4.21 & 4.5 & 95.5 & 0 \\
\hline 2 & 1.10 & 4.78 & 2.0 & 98.0 & 0 \\
\hline 3 & 1.0 & 5.26 & 0 & 100 & 0 \\
\hline 4 & 0.8 & 6.58 & 0 & 98.5 & 1.5 \\
\hline 5 & 0.6 & 8.77 & 0 & 97.5 & 2.5 \\
\hline
\end{tabular}

${ }^{a}$ Performed according to Method B in Fig. 3 . The reactor outlet was poured into a $\mathrm{NaHSO}_{3}$ solution to quench the oxidant ${ }^{b}$ Measured by gas chromatography.

Experiments were performed by varying the residence time inside the cartridge from 4.21 to $8.77 \mathrm{~min}$ (corresponding to a flow rate ranging from 1.25 to $\left.0.6 \mathrm{~mL} . \mathrm{min}^{-1}\right)$. With $t^{\mathrm{R}}<5 \mathrm{~min}$, a very good conversion was obtained $(>95 \%)$ with full selectivity toward the desired sulfoxide CEESO (entries 1 and 2). Whereas a full oxidation of the starting CEES is required, the absence of traces of the overoxidation product $\mathrm{CEESO}_{2}$ appeared very promising, which was never attained in previous reports with this oxidant. A decrease in the flow rate to $1.0 \mathrm{~mL} \cdot \mathrm{min}^{-1}\left(t^{\mathrm{R}}=\right.$ $5.26 \mathrm{~min}$ ) allowed full degradation of the toxic sulfide and only the desired harmless CEESO was generated (entry 3). In contrast, increasing the residence time (and thus the contact time with solid Oxone) provoked the formation of traces of the undesired sulfone (entries 4 and 5 ). Therefore, a range of $5<t^{R}$ $<6 \mathrm{~min}$ is essential for safe decontamination of sulfur mustard.

Based on these promising results for the selective oxidation of the S-containing blister agent simulant, it was therefore much tempting to transpose these conditions for the neutralisation of V-series OPNA. Whereas CEES is widely admitted to be the most chemically representative -and readily accessible- HD simulant, this question is much more subjected to controversy regarding organophosphorous nerve agents, especially for the V-type agents. ${ }^{42}$ Thus, whereas the phosphonothioate LG $61^{11}$ is the most used, it has a rather unsatisfying structure (Fig. 1), lacking the $\mathrm{N}(i-\mathrm{Pr})_{2}$ moiety responsible of detoxification side reactions (Fig. 2). In contrast Demeton- $\mathrm{S}^{43}$ and Tetriso ${ }^{44}$ have a-S- $\left(\mathrm{CH}_{2}\right)_{2}-\mathrm{Y}$ side chain motif closer to that of the live agent but the phosphorothioate function exhibits limitations, since its reactivity at the phosphorus centre is modified (Fig. 1).

In this line the PhX compound, developed by Renard and Mioskowski, is surely the closest alternative to $\mathrm{VX}$ : it only differs from $V X$ by a Phenyl group in place of the non-reactive methyl group and it reduces the $\mathrm{IC}_{50}$ value for acetylcholine esterase (AChE) by 60 -fold as compared to that of VX with negligible aging phenomenon (Fig. 1). ${ }^{29}$ It can thus be used in a regular academic laboratory without military clearance. First experiments were thus performed with $\mathrm{PhX}$ in the setup $\mathrm{B}$ (packed-bed reactor with Oxone). Unfortunately, no reaction occurred and the phosphonothioate was recovered unchanged (Fig. 4).§ As stated above, the Oxone-mediated decomposition of $\mathrm{PhX}$ is unclear and a water molecule intervenes at a certain point in the mechanism. In order to introduce water in the medium the Method A, with the introduction of Oxone as an aqueous solution through a second inlet was assessed. However, as for CEES, the contact between the organic agent 
and the aqueous solution led to the precipitation of salts in the flow system (Fig. 4).

Method $B$
Method $A$

The presence of a stoichiometric amount of potassium (hydrogeno)sulfate in the formulation of Oxone can be identified as the source of the issue. To circumvent this issue, a patent reported the preparation of concentrated $\mathrm{KHSO}_{5}$, with an active oxygen content (\%AO) of approximately $3.4 \%$ to $6.8 \%$, by precipitation of the accompanying salt. ${ }^{45}$ To afford this, concentrated $\mathrm{KHSO}_{5}$ commercial Oxone was reacted with aqueous potassium hydroxide according to $\mathrm{KHSO}_{4}+\mathrm{KOH} \rightarrow$ $\mathrm{K}_{2} \mathrm{SO}_{4}+\mathrm{H}_{2} \mathrm{O}$ : the accumulated $\mathrm{K}_{2} \mathrm{SO}_{4}$ during this reaction thus precipitated and after filtration, an aqueous solution containing $28 \% \mathrm{w} / \mathrm{w} \mathrm{KHSO}_{5}$ was recovered $(\% \mathrm{AO}=3.0 \%)$. ๆ This enriched solution was diluted to $1 / 3$ and used for the flow neutralization of the $V X$ simulant (Fig 4, method $A^{\prime}$ ). Delightfully, this set-up allowed full neutralization of neat $\mathrm{PhX}$ into the desired ethyl- phenylphosphonic acid within $t^{R}=10$ $\min$.

Noteworthy, the scale-up of liquid biphasic reactions is not a trivial task due to mixing issues. In flow microreactors this issue can be circumvented since the quantity of chemical that reacts inside the system remains constant. Moreover, in a miniaturized mixer, the mixing is enhanced with positive consequences on the reaction outcome. ${ }^{46}$ In a comparative study, we measured the kinetics of the decomposition of PhX into ethyl phenyl phosphonic acid (EPPA) with enriched aqueous Oxone under batch and flow conditions with ${ }^{31}$ P NMR (Table 2 and Fig. 5).

\begin{tabular}{lllll}
\hline \multicolumn{5}{l}{ Table 2. Neutralization of PhX with enriched aqueous Oxone ${ }^{a}$} \\
\hline $\begin{array}{l}\text { Reaction } \\
\text { time } \\
(\mathrm{min})\end{array}$ & $\begin{array}{l}\mathrm{Flow}^{b} \\
{[\mathrm{PhX}]} \\
\left(\mathrm{mol} . \mathrm{L}^{-1}\right)\end{array}$ & Ln $[\mathrm{PhX}]$ & $\begin{array}{l}\text { Batch }^{c} \\
{[\mathrm{PhX}]} \\
\left(\mathrm{mol} . \mathrm{L}^{-1}\right)\end{array}$ & $\mathrm{Ln}[\mathrm{PhX}]$ \\
\hline 0 & 3.43 & 1.2325 & 3.43 & 1.2325 \\
1 & 1.9208 & 0.6527 & 1.6121 & 0.4775 \\
2 & 1.5435 & 0.4340 & - & - \\
3 & 0.6860 & -0.3768 & 0.6880 & -0.3739 \\
5 & 0.2744 & -1.2931 & 0.4116 & -0.8877 \\
7.5 & 0.1029 & -2.2739 & - & - \\
8.0 & - & - & 0.1715 & -1.7631 \\
10 & 0 & - & 0 &
\end{tabular}

${ }^{a}$ Kinetic measurements were performed by taking aliquots at various intervals (quenched by $\mathrm{NaHSO}_{3}$ ) and performing ${ }^{31} \mathrm{P}$ NMR measurements. $\S$ See ESI for details. ${ }^{b}$ Flow microreactor was made of a $20.38 \mathrm{~cm}$ long PFA tubing (ID = 1.56 $\mathrm{mm}, \mathrm{V}=410 \mu \mathrm{L}$ ). ${ }^{c}$ Batch experiments were performed on a $0.1 \mathrm{~mL}$ scale in a 8 $\mathrm{mL}$-vial equipped with a stirring bar.

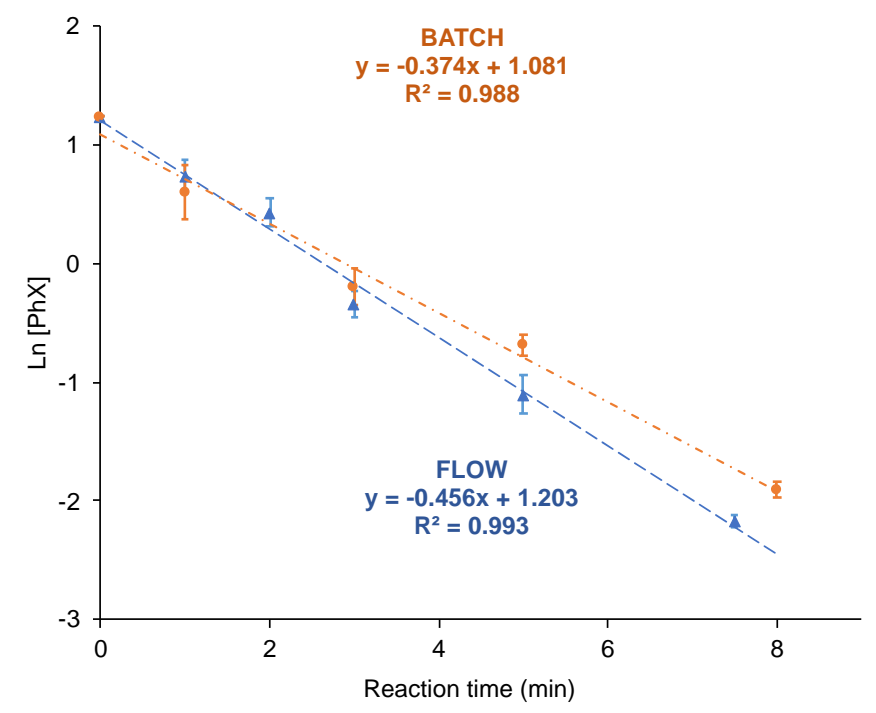

Fig.5. Reaction kinetics of neutralization of PhX into EPPA with 'enriched' aqueous Oxone under batch (orange circles) and flow (blue triangles) conditions.

Thus, under batch conditions the rate constant was measured at $k_{o b s}=0.374 \mathrm{~min}^{-1}\left(t_{1 / 2}=1.85 \mathrm{~min}\right)$ whereas it appeared to be 1.3 times faster in the fluidic system with $k_{\text {obs }}=$ $0.456 \mathrm{~min}^{-1}\left(t_{1 / 2}=1.48 \mathrm{~min}\right)$. This result seems in agreement with a reaction limited by exchanges between two phases, where a higher surface available for reaction leads to improved kinetics.

\section{Conclusions}

To summarize, we have been able to use Oxone as common efficient promoter for the oxidative flow detoxification of environmentally persistent chemical warfare agents, namely yperite (CEES) and V-series OPNA (PhX) simulants. It is worth to recall that it is mandatory for the neutralisation of CWA to take place in a fully selective manner to avoid the formation of toxic byproducts. Whereas the use of aqueous Oxone was unselective in batch and unapplicable in flow, feeding CEES in a flow system equipped with a packed-bed reactor filled with solid Oxone, the fully selective neutralization of CEES was performed. This excellent selectivity was obtained thanks to the perfect control of the reaction time allowed by flow systems: with $t^{\mathrm{R}}=5.26 \mathrm{~min}$ the reaction led exclusively to the harmless CEESO, whereas starting from $t^{R}=6.58 \mathrm{~min}$ the hazardous overoxidation product $\left(\mathrm{CEESO}_{2}\right)$ was formed. For $\mathrm{PhX}$, the neutralization took place with a flow of aqueous Oxone enriched in $\mathrm{KHSO}_{5}$ to afford the innocuous EPPA as sole product. Interestingly, kinetic measurements by mean of ${ }^{31} \mathrm{P}$ NMR analyses showed that the reaction occurs 1.3 times faster in the flow microreactor $\left(t_{1 / 2}=1.85 \mathrm{~min}\right)$ than in the batch system $\left(t_{1 / 2}=1.48 \mathrm{~min}\right)$. It is also worth noting that the decomposition path is similar to that of Yang, described on live 
VX agent. Therefore, this study also highlights the potential of $\mathrm{PhX}$ as a safer alternative to VX in neutralization studies.

\section{Acknowledgements}

SM thanks the Région Normandie for financial support for a grant in the frame of the project MILLIFLUX. The authors gratefully acknowledge the European France-(Manche)-England cross-border cooperation program INTERREG V A "LABFACT" and "SMARTT", cofinanced by ERDF, for financial support. The authors from Normandie Université also thank the Tremplin Carnot 12C, the Labex SYNORG (ANR-11-LABX-0029) and the Région Normandie for financial support.

\section{Notes and references}

¥ The lethal doses (rabbit, I.V. in $\mathrm{mg} / \mathrm{kg}$ ) are: $\mathrm{LD}_{50}(\mathrm{VX})=0.008$ $\mathrm{LD}_{50}(\mathrm{EA}-2192)=0.017 \mathrm{mg} / \mathrm{kg}$.

$\S^{31} \mathrm{P} N M R$ analyses were performed in $\mathrm{CDCl}_{3}$ with a coaxial inert containing $\mathrm{PPh}_{3}$ calibrated at $\delta=5 \mathrm{ppm} . \delta(\mathrm{PhX})=45.4 \mathrm{ppm}$, $\delta($ EPPA $)=18.4 \mathrm{ppm}$.

I The solubility of commercial Oxone is $300 \mathrm{~g} / \mathrm{L}$ of water corresponding to $11.4 \% \mathrm{w} / \mathrm{w} \mathrm{KHSO}_{5}$, corresponding to $\% \mathrm{AO}=$ $1.2 \%$.

1 D. Hafemeister, in Nuclear Proliferation and Terrorism in the Post-9/11 World, Springer International Publishing, Cham, 2016, pp. 337-351.

$2 \quad$ M. Peplow, Chem. Eng. News, 2018, 96, 3.

3 H. John, M. J. van der Schans, M. Koller, H. E. T. Spruit, F. Worek, H. Thiermann and D. Noort, Forensic Toxicol., 2018, 36, 6171.

4 G. Mercey, T. Verdelet, J. Renou, M. Kliachyna, R. Baati, F. Nachon, L. Jean and P.-Y. Renard, Acc. Chem. Res., 2012, 45, 756766.

$5 \quad$ X. Li, J. Dong, H. Liu, X. Sun, Y. Chi and C. Hu, J. Hazard. Mater., 2018, 344, 994-999.

$6 \quad$ I. A. Fallis, P. C. Griffiths, T. Cosgrove, C. A. Dreiss, N. Govan, R. K. Heenan, I. Holden, R. L. Jenkins, S. J. Mitchell, S. Notman, J. A. Platts, J. Riches and T. Tatchell, J. Am. Chem. Soc., 2009, 131, 9746-9755.

7 G. W. Wagner, L. R. Procell, Y.-C. Yang and C. A. Bunton, Langmuir, 2001, 17, 4809-4811.

8 F. Gonzaga, E. Perez, I. Rico-Lattes and A. Lattes, New J. Chem., 2001, 25, 151-155.

9 Y.-C. Yang, Acc. Chem. Res., 1999, 32, 109-115.

10 Y. C. Yang, L. L. Szafraniec, W. T. Beaudry and D. K. Rohrbaugh, J. Am. Chem. Soc., 1990, 112, 6621-6627.

11 B. Smolkin, N. Levi, N. Karton-Lifshin, L. Yehezkel, Y. Zafrani and I. Columbus, J. Org. Chem., 2018, 83, 13949-13955.

12 N. Karton-Lifshin, S. Katalan, I. Columbus, R. Chen, L. Yehezkel, M. Madmon, S. Dagan, S. Elias, G. Fridkin and Y. Zafrani, Chem. Commun., 2019, 55, 12471-12474.

13 B. Picard, K. Pérez, T. Lebleu, D. Vuluga, F. Burel, D. C. Harrowven, I. Chataigner, J. Maddaluno and J. Legros, J. Flow Chem., 2020, 10, 139-143.

14 K. Pérez, B. Picard, D. Vuluga, F. Burel, R. Hreiz, L. Falk, J.M. Commenge, A. Nagaki, J. Yoshida, I. Chataigner, J. Maddaluno and J. Legros, Org. Process Res. Dev., 2020, 24, 787-791.

15 T. Lebleu, J. Maddaluno and J. Legros, Org. Chem. Front., 2015, 2, 324-327.
16 A. Nagaki, H. Kim and J. Yoshida, Angew. Chem. Int. Ed., 2009, 48, 8063-8065.

17 A. Nagaki, D. Ichinari and J. Yoshida, Chem. Commun., 2013, 49, 3242.

18 J. Yoshida, A. Nagaki, T. Iwasaki and S. Suga, Chem. Eng. Technol., 2005, 28, 259-266.

19 H. Kim, A. Nagaki and J. Yoshida, Nat. Commun., 2011, 2,

264.

20 H. Kim, K.-I. Min, K. Inoue, D. J. Im, D.-P. Kim and J.

Yoshida, Science, 2016, 352, 691-694.

21 M. Movsisyan, E. I. P. Delbeke, J. K. E. T. Berton, C. Battilocchio, S. V. Ley and C. V. Stevens, Chem. Soc. Rev., 2016, 45, 4892-4928.

22 D. Dallinger, B. Gutmann and C. O. Kappe, Acc. Chem. Res., 2020, 53, 1330-1341.

23 B. Picard, B. Gouilleux, T. Lebleu, J. Maddaluno, I.

Chataigner, M. Penhoat, F.-X. Felpin, P. Giraudeau and J. Legros, Angew. Chem. Int. Ed., 2017, 56, 7568-7572.

24 N. Emmanuel, P. Bianchi, J. Legros and J.-C. M. Monbaliu, Green Chem., 2020, 22, 4105-4115.

25 Y. J. Jang, K. Kim, O. G. Tsay, D. A. Atwood and D. G.

Churchill, Chem. Rev., 2015, 115, PR1-PR76.

26 T. Islamoglu, Z. Chen, M. C. Wasson, C. T. Buru, K. O.

Kirlikovali, U. Afrin, M. R. Mian and O. K. Farha, Chem. Rev., 2020, 120, 8130-8160.

27 M. M. Y. Motamedhashemi, F. Egolfopoulos and T. Tsotsis, J. Membr. Sci., 2011, 376, 119-131.

28 A. A. Wang, W. Chen and A. Mulchandani, Biotechnol. Bioeng., 2005, 91, 379-386.

29 P.-Y. Renard, H. Schwebel, P. Vayron, L. Josien, A. Valleix

and C. Mioskowski, Chem. - Eur. J., 2002, 8, 2910-2916.

30 H. Hussain, I. R. Green and I. Ahmed, Chem. Rev., 2013, 113, 3329-3371.

31 S. Popiel, Z. Witkiewicz and A. Szewczuk, J. Hazard.

Mater., 2005, 123, 94-111.

32 B. Yu, A.-H. Liu, L.-N. He, B. Li, Z.-F. Diao and Y.-N. Li,

Green Chem., 2012, 14, 957-962.

33 J. Yoshida, A. Nagaki, T. Iwasaki and S. Suga, Chem. Eng. Technol., 2005, 28, 259-266.

34 K. Midorikawa, S. Suga and J. Yoshida, Chem. Commun., 2006, 3794-3796.

35 H. Usutani, Y. Tomida, A. Nagaki, H. Okamoto, T. Nokami and J. Yoshida, J. Am. Chem. Soc., 2007, 129, 3046-3047.

36 A. Nagaki, C. Matsuo, S. Kim, K. Saito, A. Miyazaki and J.

Yoshida, Angew. Chem. Int. Ed., 2012, 51, 3245-3248.

37 H. S. N. Lee, M. T. Sng, C. Basheer and H. K. Lee, J.

Chromatogr. A, 2008, 1196-1197, 125-132.

38 M. Krivec, A. Pohar, B. Likozar and G. Dražić, AlChE J., 2015, 61, 572-581.

39 L. Suhadolnik, A. Pohar, B. Likozar and M. Čeh, Chem. Eng. J., 2016, 303, 292-301.

40 L. Suhadolnik, D. Lašič Jurković, B. Likozar, M. Bele, S. Drev and M. Čeh, Appl. Catal. B Environ., 2019, 257, 117894.

41 F. Silva, A. Baker, J. Stansall, W. Michalska, M. S. Yusubov, M. Graz, R. Saunders, G. J. S. Evans and T. Wirth, Eur. J. Org. Chem., 2018, 2018, 2134-2137.

42 B. Picard, I. Chataigner, J. Maddaluno and J. Legros, Org.

Biomol. Chem., 2019, 17, 6528-6537.

43 V. Vallet, C. Cruz, J. Licausi, A. Bazire, G. Lallement and I.

Boudry, Toxicology, 2008, 246, 73-82.

44 Y. J. Rosenberg, J. Walker, X. Jiang, S. Donahue, J.

Robosky, M. Sack, J. Lees and L. Urban, Sci. Rep., , 
DOI:10.1038/srep13247.

45 World Intellectual Property Organization,

WO2007143127A1, 2007.

46 J. Yoshida, H. Kim and A. Nagaki, ChemSusChem, 2011, 4,

331-340. 